\title{
Simulation, computation and dynamics in economics
}

\section{K. Vela Velupillai \& Stefano Zambelli}

To cite this article: K. Vela Velupillai \& Stefano Zambelli (2015) Simulation, computation and dynamics in economics, Journal of Economic Methodology, 22:1, 1-27, DOI:

10.1080/1350178X.2015.1004933

To link to this article: http://dx.doi.org/10.1080/1350178X.2015.1004933

曲 Published online: 17 Feb 2015.

Submit your article to this journal ¿

Џ Article views: 265

Q View related articles $₫$

View Crossmark data ¿ 


\title{
Simulation, computation and dynamics in economics
}

\author{
K. Vela Velupillai ${ }^{\mathrm{a} *}$ and Stefano Zambelli ${ }^{\mathrm{b} *}$ \\ ${ }^{a}$ Department of Economics, The New School for Social Research, New York, NY 10003, USA; \\ ${ }^{b}$ The Algorithmic Social Sciences Research Unit, Department of Economics, University of Trento, \\ Trento, Italy
}

(Received 12 December 2012; accepted 29 January 2014)

\begin{abstract}
Computation and Simulation have always played a role in economics - whether it be pure economic theory or any variant of applied, especially policy-oriented, macro- and microeconomics or what has increasingly come to be called empirical or experimental economics. Computations and simulations are also intrinsically dynamic. This triptych computation, simulation and dynamic - is given natural foundations, mainly as a result of developments in the mathematics underpinnings in the potentials of computing, using digital technology. A running theme in this essay is the recognition that, increasingly, the development of economic theory seems to go hand in hand with advances in the theory and practice of computing, which is, in turn, a catalyst for the move away from too much reliance on any kind of mathematics for the formalisation of economic entities that is inconsistent with the mathematical, methodological and epistemological foundations of the theory of computation.
\end{abstract}

Keywords: simulation; computation; dynamics; computable; constructive; proof; algorithm

Jel Classification: B41; C63; C65; C68; D58

\section{Simulation, dynamics and computation: A brief preamble}

Ulam first used 'synergesis' in the context of the 'Computing machine as a heuristic aid' in mathematical research .... This was a new mode of working. ....

From 'synergesis,' I formulated the visiometrics approach ... Visiometrics is the process of producing cogent 2D and 3D images and parameter-scaled (normalized) graphs for developing intuition and aiding in mathematical model formation. (Zabusky, 2005, p. 10; italics added)

The art of gleaning epistemological lessons, from simulating a mathematical model generating dynamic behaviour, on a (digital) computer, was elegantly outlined by Weissert (1997, p. 106; italics added), in the context of the famous Fermi-Pasta-Ulam problem (Fermi, Pasta, \& Ulam, 1955), which was the setting for Zabusky's path from 'synergesis' to 'visiometrics':

The goal of simulation in dynamics is to learn about the true solution by simulating the trajectories of the associated differential equations... Whether or not the true solution of a model actually relates to physical reality depends upon the fundamental laws used and the approximations made to obtain the model. As the simulation teaches us about the true solution, we make decisions about the adequacy of the model. Simulation's function is to reveal the properties of the true solution and to aid our decisions about how well the model suits the physical system. As doubts arise about the model's adequacy, but we are reasonably confident of the simulation, we must turn our attention to the approximations made in the model. Several

*Corresponding authors. Email: kvelupillai@gmail.com; stefanozamb@gmail.com 
times .... a researcher indicates an implicit belief that the simulation does tell us something about the physical reality. Such an [indication] implies a trust in a long chain of inferences and approximations beginning from the adequacy of the fundamental theory itself, to the equivalency of an infinite series expansion of terms, then to the approximations that are made to obtain a model, and finally to the simulation and what it might be telling us about the model.

Weissert's concise, yet elegant, encapsulation of a research program on the epistemology of simulation in dynamics leaves a few crucial questions un-broached. First of all, even if there is such a thing as one 'true solution of a model', the means - i.e., the methods of proof - used to demonstrate the existence of such a true solution of a model, in theory, may or may not provide any information on the 'adequacy of the model' and 'how well [it] suits the physical system' it aims to 'model'. Second, 'the approximations [to the physical system]' to obtain the model may not be definable uniquely. Third, the methods of approximations may not be independent of the methods of proof used to demonstrate the existence of a true solution. Fourth, unless the chosen methods of approximations are very carefully selected most models that are even reasonably faithful - in any one of many possible ways of 'defining' this tortuous term - cannot be forced to yield unique solutions. Finally, and most disturbingly, from the point of view of simulation of the dynamics of 'the trajectories of the differential equations' associated with the model, by machine computation - i.e., by, say, a digital computer - is the following question: can a dynamical system, whose equilibrium existence - i.e., 'true solution of a model' - is proved by non-finite means, be simulated by finite means to obtain epistemological answers to questions on the 'true solution of a model'?

Let us illustrate this last point more explicitly. Consider one possible elementary statement of the Peano existence theorem for the initial value problem (IVP) of ordinary differential equations (ODEs), (Iserless, 1996, pp. 364-365; italics added):

Let the function $f:\left[t_{0}, t_{0}+a\right] \times U \rightarrow \mathbb{R}^{d}$ (where : $U \sqsubseteq \mathbb{R}^{d}$ ) be continuous in the cylinder:

$$
S=\{(t, \mathbf{x})\}: t \in\left(t_{0}, t_{0}+a\right), \quad \mathbf{x} \in \mathbb{R}^{d},\left\|x-y_{0}\right\| \leq b,
$$

where: $a, b>0$ and the vector norm $\|\cdot\|$ is given. Then, the ODE:

$$
\mathbf{y}^{\prime}=f(t, \mathbf{y}), t \in\left(t_{0}, t_{0}+\alpha\right), \quad \mathbf{y}\left(t_{0}\right)=\mathbf{y}_{0} \in \mathbb{R}^{d},
$$

where $\alpha=\min \{a, b / \mu\}$ and $\mu=\sup _{(t, x) \in S}\|f(t, x)\|$ possess at least one solution

However, it can be shown that $\exists f(t, y)$, satisfying the hypotheses of the Peano existence theorem, such that there is no solution to the IVP (Aberth, 2001). Why is this so? This is because the existence of a solution violates a cardinal theorem of computable calculus: the Unsolvability of the Halting Problem for Turing Machines. More specifically, there are a series of nonsolvable problems by finite means, in the computable calculus, some of which have to be made solvable by non-finite means for the Peano existence theorem to be satisfied. In the case of the Peano existence theorem, the relevant nonsolvable problems are:

Proposition 1. It is undecidable (by finite means) whether, $\forall a \in R, a$ or $\sim a$ is rational.

Proposition 2. It is undecidable (by finite means) whether, $\forall a \in R, a \geq 0$ or $a \leq 0$. 
Thus, implicit in any standard proof of the Peano existence theorem there are appeals to non-finite means to decide (intrinsically undecidable) disjunctions. No amount of simulation, even by an 'ideal' computer - say, Turing Machine (or any of its equivalents, by the Church-Turing Thesis) - can contribute epistemologically to any question about the 'true solution of a model', which is analytically fully characterised, but using standard real analysis underpinned by set theory plus the axiom of choice.

However, it must be noted that Peano went out of his way to avoid any appeal to the axiom of choice in his proof. Furthermore, Peano dropped the assumption of the Lipschitz. condition in his original paper of 1890 (thereby losing uniqueness, Ince, 1944, p. 66). Indeed, it was during the course of this proof that the ubiquity of this controversial axiom was first recognised and avoided. ${ }^{1}$

This is, by the way, an instance of the ignorance of alternative mathematical traditions and careless understanding of the underpinning axioms which leads, in turn, to ignorant assertions on the interactions between simulation, mathematical formalisms, formal solutions, approximations and so on. ${ }^{2}$

But what is a computation? The lucid, elementary, answer to this question, entirely in terms of computability theory was given by Martin Davis in a masterly exposition (Davis, 1978). Here, we are interested in an answer that links computation and simulation.

We shall assume the following 'claims' to try to come to grips with a possible answer to the question, 'What is a computation', in a meaningful sense.

Claim 3. Every computation is a dynamical system

Claim 4. Every simulation of a dynamical system is a computation

What can we know, what must we do and what can we hope from a computation, which is, by the above claim, a dynamical system? This, in turn, means what can we know, what must we do and what can we hope from studying the behaviour of a dynamical process during a computation? Since, however, not everything can be computed, it follows that not every question about a dynamical system can be answered unambiguously. But by the second of the above-mentioned claims, we have expressed an 'identity' between a simulation and a computation, via the intermediation of a dynamical system, which implies that not everything can be learned about the behaviour of a dynamical system by simulating it on (even) an ideal device that can compute anything that is theoretically computable (i.e., a Turing Machine, assuming the Church-Turing Thesis). Above all, we cannot delineate, in any meaningful sense - i.e., in an algorithmically decidable sense between what can be known or learned and that which lies 'beyond' this undecidable, indefinable, border, on one side of which we live our scientific lives.

Now, observe the following:

An argument deriving the truth of a universal arithmetical sentence from that of its numerical instances suggests that the truth of the numerical instances has some kind of epistemological priority over the truth of the sentence itself: our knowledge of the truth of the sentence stems from the fact that we know all its numerical instances to be true... I shall show that it is just the other way around. ... [T] he source of our knowledge of the truth of the totality of its numerical instances is the truth of the sentence itself. (Serény, 2011, p. 48; italics added)

Juxtapose this inversion of 'epistemological priority' between the 'truth of a universal arithmetical sentence' and 'the totality of its numerical instances' - remembering that the latter is obtained by computations - with Cohen's causal conjecture between 'the revolution in computing' and 'its inspiration in mathematics': 
Hilbert's vision of a universal algorithm to solve mathematical theorems ${ }^{3}$ required a unification of Logic, Set Theory and Number Theory. This project was initiated by Frege, rerouted by Russell, repaired by Whitehead, derailed by Gödel, restored by Zermelo, Frankel, Bernays and von Neumann, shaken by Church and finally demolished by Turing. Hence, to say that the interest in algorithmic methods in mathematics or the progress in logic was engendered by the computer is wrong way around. For these subjects it is more correct to observe the revolution in computing that was inspired by mathematics. (Cohen, 1991, p. 323; italics added)

The rest of the article is organised as follows. In the next section, a brief outline is given of the main fields in economics where reliance on (digital) computation, enhanced by the possibilities of 'learning by simulation', plays significant roles. In Section 3, an example of learning new alternatives of dynamics, by digital simulation, is given. Section 4 discusses the alternative duality, that between computation and simulation, in implementing conjectures and constructing (digital) machine-based proofs - a field that is unbroached in economics in the mathematical mode. The concluding section is a kind of hope for a new research tradition, taking seriously the mathematics underpinning the digital computer and learning to explore the limits of them - the mathematics and the digital computer - for exploring new frontiers in economics, but based on the rich tradition of the subject. We attempt to summarise, as concisely as possible, the core areas of economics which initiated and maintained what we call 'the noble tradition of simulation in economics' with reflections and hopes on what must be done to keep the bright shining light of computation, simulation and dynamics focused on economic theory and its formalisation.

\section{Simulation and computation in economics}

There are at least five frontier research fields in economics, encompassing both micro and macro aspects of economic theory, where machine computation ${ }^{4}$, in its digital mode, enriched by simulational exercises, is claimed to play crucial roles in formal modelling exercises ${ }^{5}$ :

1. Computable General Equilibrium Theory (CGE) (and its 'extensions': Recursive Competitive Equilibrium (RCE) \& Dynamic Stochastic General Equilibrium (DSGE) theories) - The Scarf Tradition.

2. Computable General Equilibrium Modelling - The Johansen-Stone Tradition (cf., Johansen, 1960 (1974), Dixon \& Parmenter, 2009).

3. Agent-based computational economics (cf., Tesfatsion, 2006, Epstein, 2006). ${ }^{6}$

4. Classical behavioural economics (CBE, as distinct from MBE: Modern behavioural economics, see Velupillai \& Kao, 2014).

5. Computable economics ${ }^{7}$.

That CGE in the Scarf Tradition is not underpinned by either computable or constructive mathematics is, by now, fairly well known (cf., Velupillai, 2010) But it is less well documented that the claims of computability of the Johansen-Stone tradition is equally untenable. Therefore some comments may be in order.

Somewhat surprisingly, the adherents and aficionados of Leif Johansen's classic work on A Multi-Sectoral Study of Economic Growth (Johansen, 1960 [1974]) claim that this was 'the first CGE model' (Dixon \& Parmenter, op.cit., p. 6). Their rationale for this claim is the following (p. 6; last two italics, added):

[The Johansen model] was general in that it contained.. cost minimizing industries and utilitymaximizing household sectors.... His model employed market equilibrium assumptions in the determination of prices. Finally, it was computable (and applied). It produced a numerical, multi-sectoral description of growth in Norway using Norwegian input-output 
data and estimates of household price and income elasticities derived using Frisch's ... additive utility method.

This is an untenable claim ${ }^{8}$ The Johansen model has no underpinning whatsoever in any formal model of computation, least of all a computable (or constructive) one.

There is a serious epistemological deficit in all of the approaches, but can be discovered only in the last two, precisely because the latter are underpinned by computability and constructivity theories, in their strict mathematical senses, and the former are not (see the appendix to this section). However, this claim does not imply that classical behavioural economics and computable economics are 'complete' from an epistemological perspective, especially from the point of view of natural or intrinsic dynamics of formal models. The epistemological deficit and the epistemological incompleteness, it is suggested, can be resolved by a theory of simulation, itself based on recognising the double 'duality' between dynamical systems and numerical analysis, on the one hand, and that between computation and simulation, mediated by dynamical systems, both 'dualities' interpreted computably or constructively, leading to the core triad of computation, simulation and dynamics (because numerical analysis can be interpreted, equivalently, in terms of dynamical systems or computability). Hence, hopefully, paying heed to Turing's Precept: 'the inadequacy of "reason" unsupported by common sense.'

We end this preliminary reflection on a computably underpinned simulational approach to a discussion of the epistemological deficit intrinsic to the interlinked triad of computation, simulation and dynamics by invoking Feynman on our side:

Computer science touches on a variety of deep issues. .... It naturally encourages us to ask questions about the limits of computability, about what we can and cannot know about the world around us. (Feynman, 1996, p. xiii; italics added)

One final remark on a classic in the rich interaction between simulation, computation and dynamics is, we feel, appropriate, here. In their fascinating recapitulation of the circumstances under which Fermi, Pasta and Ulam tried to resolve a theoretical conundrum - and still completely unresolved - with a discrete approximation of a continuum model implemented on one of the first available digital computers - the MANIAC - Porter, Zabusky, Hu, and Campbell (2009) point out the many ways in which the simulations interacted with the analytical theory to enrich both in surprising ways. The methodological implications, of the interaction between computation and dynamics via a series of simulations that have been implemented, with increasing precision, detail and generalisations in the 55 years since the original 'experiment', are exhaustively discussed and dissected in the admirable monograph by Thomas Weissert ${ }^{9}$ (op.cit). As Porter et al. perceptively ${ }^{10}$ note (2009, pp. 214-216; italics added):

....Fermi had long been fascinated by a fundamental mystery of statistical mechanics that physicists call the 'arrow of time' [irreversibility]. .... Fermi believed that the key [to the unlocking of the mystery of irreversibility] was nonlinearity .... He knew that it would be far too complicated to find solution to nonlinear equations using pencil and paper. Fortunately, because he was at Los Alamos in the early 1950s, he had access to one of the earliest digital computers [the MANIAC]. .... The FPU problem was one of the first open scientific investigations carried out with the MANIAC, and it ushered in the age of what is sometimes called experimental mathematics. ..... [by] which we mean computer-based investigations designed to give insight into complex mathematical and physical problems that are inaccessible, at least initially, using more traditional forms of analysis. .... With Pasta and Ulam, Fermi proposed to investigate what he assumed would be a very simple nonlinear dynamical system... The Key question FPU wanted to study was how long it would take the oscillations of the masses and nonlinear springs to come to equilibrium. ... They were absolutely astonished by the results. 
The FPU problem exemplifies many interesting, even unresolvable, aspects of the felicitous link between computation, dynamics and simulation. One of us (see Zambelli, 2011) has attempted to resolve dynamic perplexities by structured simulation studies, in close combination with established macrodynamic and interindustrial economics, formalised computably.

\section{A Visiometrics and the graph theorems}

The problems of scientific computing often arise from the study of continuous processes, and questions of computability and complexity over the reals are of central importance in laying the foundations for the subject. The first step is defining a suitable computational model for functions over the reals. Braverman and Cook (2006, p. 318); italics added.

Of the five frontier research fields in economics claiming computational underpinnings, mentioned above, only the first and the last two are explicitly based on 'a suitable computational model for functions over the reals'. Moreover, both classical behavioural economics and computable economics are either explicitly or implicitly defined over the computable, constructive or non-standard reals. However, computable general equilibrium theory (in the Scarf mode), even though it is defined over the reals, does not develop its theory on a model of computation that is consistent with its basis on all of the standard reals (a fortiori for recursive competitive equilibrium (RCE) and DSGE). Neither computable general equilibrium economics (in the Johansen-Stone mode), nor agent-based computational economics (and finance), are based on any kind of formal (or informal) 'computational model over the reals'. None of the above-mentioned five frontier research fields, except every kind of agent-based computational economics (and finance) practice ${ }^{11}$ rely overwhelmingly on an elementary - and undefined - kind of Visiometrics, appealing to computer graphics, without the slightest basis in the mathematics of the computer (of any variety). In this brief appendix, we outline the kind of care needed to make sense of the excessive claims of the practitioners of agent-based computational economics (and finance), ${ }^{12}$ so that they can be brought into the fold of serious Visiometrics. ${ }^{13}$

Zabusky's more discursive description - we shall not call it a formal definition - of what he means by Visiometrics is something like the following (loc.cit, p.12; italics in the original):

VISIOMETRICS is the process of: Visualization, projection, identification and juxtaposition of evolving amorphous coherent structures and statistical backgrounds in massive multidimensional data sets. The goal is to produce cogent images and specific, parameterscaled (normalized) graphs for intuition building and mathematization.

The crucial terms are 'cogent images' and 'graphs for intuition building and mathematization', especially in the case of economic visiometrics, where the 'massive multidimensional data sets' reside, at best, in the set of rational numbers.

Essentially, all of the above-mentioned five frontier computational economic research areas theorise in the domain of the real numbers and real number functions (of arbitrary high dimensions), but agent-based computational economics, in particular, seeks to extract patterns from the projected dynamics on the screens of digital computers (there are, of course, enlightened exceptions to this general rule). If the theorising is in terms of real analysis, then the 'graphs' of theory are subject to the classical graph theorem:

Theorem 5. The 'Classical' Graph Theorem: A function (or mapping or transformation), 
$\psi: A \rightarrow B$ is any subset $\psi \subseteq(A \times B)$ such that $(\forall x \in A)(\exists ! y \in B) \&[(x, y) \in \psi]$ and $(\forall x \in A)(y \in B),[(x, y) \in \psi] \&\left[\left(x, y^{\prime}\right) \in \psi \Rightarrow y=y^{\prime}\right]$

Where: $A$ : Domain set; $B$ : Range set: ! : $\exists$ exactly one;

Theorem 6. The Recursion Theoretic Graph Theorem: Let $\phi$ and $\xi$ be, respectively, a partial and a total function. Then:

1. $\phi$ is partial recursive iff its graph is a recursively enumerable set;

2. $\xi$ is recursive iff its graph is a recursive set;

To these theorems we would like to add, and invoke, what we call Brattka's Theses (Brattka, 2008):

Criterion 7. Brattka's Thesis I: A function $\zeta: \mathbb{R}^{n} \rightarrow \mathbb{R}$ is computable iff it can be evaluated on a physical computer with arbitrary given precision.

Criterion 8. Brattka's Thesis II: A closed subset $\Phi \subseteq \mathbb{R}^{2}$ is recursive iff it can be displayed by a physical computer for an arbitrary given resolution.

Conjecture 9. No function employed in any agent-based computational model satisfies either of Brattka's Theses.

Remark 10. This is too strong a conjecture; we should be more specific about the particular agent-based model. However, we want only to give a flavour of the kind of conditions that have to be satisfied for some of the enthusiastic, vague and imprecise claims to be valid.

From these theorems and criteria any discerning reader can understand why we claim that classical behavioural economics and computable economics are eminently suitable for Visiometric explorations. Moreover, these theorems and criteria are also the reasons why we made 'the main claim' of this article, mentioned above.

\section{Discovering dynamics by simulation in macroeconomics}

Progress in our understanding of the natural sciences has always depended upon the give-andtake between modelling (or theorising), analysis and experiment. With large-scale computers, we can process experimental data from a variety of sensors and juxtapose them readily with large-scale simulations - numerical solutions of ordinary and partial differential equations, etc. The insights gained from attempting to bring these results into agreement can synergise ${ }^{14}$ the rate of improvement of models, algorithms, analytical methods and experimental procedures. Zabusky (1981, p. 236); italics added.

Consider the following nonlinear equation:

This can be represented as:

$$
\epsilon \frac{\mathrm{d}^{2} x}{\mathrm{~d} t^{2}}+\left(x+x^{2}\right) \frac{\mathrm{d} x}{\mathrm{~d} t}+x+\alpha=0
$$

$$
\begin{gathered}
\frac{\mathrm{d} x}{\mathrm{~d} t}=\epsilon^{-1}(y-f(x)) \\
\frac{\mathrm{d} y}{\mathrm{~d} t}=-(x+\alpha)
\end{gathered}
$$


and the 'characteristic' $f(x)$, is given by:

$$
f(x)=\frac{1}{3} x^{3}+\frac{1}{2} x^{2}
$$

For $\alpha=0$ and if $(1 / 2) x^{2}$ is replaced by $x$, the system reduces to the classic van der Pol equation on the Liénard plane. ${ }^{15}$

It is clear that $y$ is the 'slow' variable; i.e., it is finite for all finite points of the domain of the plane; $x$, then, is the 'fast' variable and takes infinitely large values for some finite values of its domain. If the trajectory of $y$ is defined to be on that curve at which $\dot{x}=0$, then its graph is given by $f(x)$.

The proof of existence of counter-intuitive cycles being attracted to unstable manifolds, for the van der Pol system, is straightforward. Let us simply state it, in as heuristic and intuitive way as possible, to illustrate what we mean; the interested reader can get a clear idea from the exceptionally clear and detailed article by Zvonkin and Shubin (1984). The only thing to keep in mind is that $\alpha$ is an infinitesimal in the sense of non-standard analysis. Then, ${ }^{16}$ (Zvonkin \& Shubin, op. cit., §4.2):

Definition 11. An admissible form for the characteristic, $f(x)$.

$f(x)$ has an admissible form on a closed interval, say $\left[\beta_{1}, \beta_{2}\right]$, if:

(1) $f(x) \in\left[\beta_{1}, \beta_{2}\right]$ is standard and $\mathbb{C}^{2}$;

(2) $f(x) \in\left[\beta_{1}, \beta_{2}\right]$ has exactly two isolated extremum points, say a minimum at $x_{0}$, and a maximum at $x_{1}$, and $\beta_{1}<x_{1}<x_{0}<\beta_{2}$, so that: $f^{\prime}(x)>0$ on $\left[\beta_{1}, x_{1}\right)$ and $\left(x_{0}, \beta_{2}\right]$ and $f^{\prime}(x)<0$ on $\left(x_{1}, x_{0}\right)$;

(3) $f\left(\beta_{1}\right)<f\left(x_{0}\right)$ and $f\left(\beta_{2}\right)>f\left(x_{1}\right)$;

Theorem 12. Existence of 'counter-intuitive' cycles in the van der Pol system [(2) or (3)(5)].

Suppose $f(x)$ has an admissible form on $\left[\beta_{1}, \beta_{2}\right]$; if $x_{\beta} \in \Re$ and $x_{\beta} \in\left(x_{1}, x_{0}\right)$, then $\exists$ value of the infinitesimal $\alpha$, for which the van der Pol system has a 'counter-intuitive' cycle, for which the location of $x_{\beta}$ is precisely identifiable.

The point of the exercise is that a knowledge of the possibilities for exploring a dynamical system with parameters and variables taking infinitesimal and infinite values is indispensable - not just for reasons of pure mathematical aesthetics; but also for eminent economic reasons. An economist, narrowly trained in standard mathematics will always have to resort to ad hockeries to handle the infinitesimal and the infinity - for example, in models capable of relaxation oscillations. Quite apart from aesthetics and pragmatics, it is also the case that the mathematics of non-standard analysis is intuitively natural and much simpler, without all the artificial paraphernalia of the ' $\varepsilon-\delta$ ' calisthenics.

But the purist may wonder whether the mathematics of the digital computer, on which the above simulations helped us 'discover' counter-intuitive dynamics, is faithful to the underpinning logic of algorithmic mathematics. Without the space to go into details we may refer the interested reader to Palmgren (2001) and Laugwitz (2001), where, particularly in the former, there is a concerted - and we believe successful - attempt is made to reconcile the constructive and the non-standard worlds of mathematical analysis.

Suppose, now, we are made aware of Ralph Abraham's conjectures on stability (Abraham, 1985, pp. 120-121; underlined emphasis in the original): 
The ubiquity of structurally unstable motions .... suggests that structural stability is not an appropriate concept for experimental systems.... Here we may hazard a conjecture: all natural systems are dynamically stable. In fact, we will probably evolve the definition of stability until this conjecture becomes true.

Simultaneously we, as economists, recall Leontief's characteristically perceptive observation (Goodwin, 1953, p. 68; italics added):

Professor Leontief does not accept [that instability is an unrealistic hypothesis] and maintains that we may utilize dynamical systems that are unstable throughout and cites capitalism as an example.

The question, then, is: whether dynamic economics (aggregative or not), modelled as a (nonlinear) dynamical system, is a natural system (Abraham), an experimental system (Abraham) or an empirical system (Leontief)? There is no a priori reason for any of these kinds of dynamical systems to be stable for observational, simulational or experimental purposes (Plott \& Smith, 1999) - especially also since it is easy to show that only dynamical systems incapable of being underpinned by any notion of maximisation (Samuelson, 1970 [1972], p. 12) are capable of computation universality and, hence, consistent with the standard assumption of rationality in economics. ${ }^{17}$

Finally, the simulated dynamics, on only a 'laptop' computer, illustrate unambiguously, the precepts for the synergy enunciated by Norman Zabusky with which we started this section: 'The insights gained from attempting to bring these results into agreement can synergize the rate of improvement of models, algorithms, analytical methods, and experimental procedures.' The two most important, unexpected or surprising improvements were the generation, entirely by the simulation of an orthodox dynamical system, of the counterintuitive notion of a trajectory attracted to an unstable manifold, justified by an 'alternative' mathematical formalism. Economists, in particular, schooled for centuries on a particularly narrow vision of what Paul Samuelson quite perceptively referred to as the 'dogma of stability' (Samuelson, 1974, p. 10) in business cycle theorising, and almost totally ignorant of alternative mathematical formalisms, have much to gain from what we should henceforth refer to as the Zabusky Precept. ${ }^{18}$

\section{Computation, discretisation, proof and simulations}

[T]here is, strictly, no such thing as mathematical proof; that we can, in the last analysis, do nothing but point ${ }^{19}$; that proofs are what Littlewood and I call gas, rhetorical flourishes designed to affect psychology, pictures on the board in the lecture, devices to stimulate the imagination of pupils. This is plainly not the whole truth, but there is a good deal in it. Hardy (1929, p. 18); italics in the original

In discussions of the interaction between individual rational behaviour and equilibrium, an equilibrium that is used to solve an analytical problem is based on mutual expectations. This, in turn, requires a resolution of an infinite regress in mutual expectations.

Essentially, one is groping towards a definition of a Nash equilibrium. It is, then, frequently claimed that ${ }^{20}$ :

'Computers cannot model such an infinite regress';

Computers, are 'based on ${ }^{21}$ constructive mathematics';

Constructive mathematics 'cannot handle' infinite regress.

We shall take these claims in the above order. First of all, it is plainly incorrect that 'computers cannot handle an infinite regress'. The infinite regress in expectation in 
economics and game theory is usually 'broken' by the utilisation of one or another fix point theorem, usually non-constructive and uncomputable ones. There are eminently respectable constructive and computable fixed points that can be utilised to 'break' the infinite regress emerging from the potential indeterminacies of mutual expectations. In Velupillai (2007, §4), we have, in fact, devised and derived a perfectly well-defined rational expectations equilibrium using the standard mathematics of the computer - i.e., 'recursion theory'. Moreover, there is an eminently rigorous fixed point theorem in constructive mathematics, derived and proved constructively, on the basis of intuitionistc logic, by no less an authority than Brouwer (1952), which can be used to define the kind of equilibrium with the infinite regress of mutual expectations.

The caveat to these objections and our counter-claims are, of course, the implication that one must go back to the proverbial 'drawing board' and formalise the basic closures of economic theory - especially preferences and endowments, but technology, too, eventually - either in recursion theoretic terms or constructively. Both of these enterprises are feasible, have been achieved successfully and are, then, entirely consistent with using either a computer running on recursion theoretic principles or on constructive mathematics foundations. $^{22}$

Second, it is simply not true that computers - i.e., any standard, working, digital computer - and their associated workings are 'based on constructive mathematics'. In every standard, working, digital computer, the mathematical basis is recursion theory (computability theory), if anyone cares to think deeply enough about it. It is not as if one cannot make a working computer on the basis of constructive mathematics, or even make the standard Turing Machine realisation implement programs written in a language adapting some version of constructive mathematics. ${ }^{23}$

Third, it is absolutely false that constructive mathematics 'cannot handle infinite regress'. It is entirely feasible to handle varieties of 'infinite regress' within constructive mathematics, except that the kind of 'infinities' are more carefully defined and invoked and, therefore, the nature of economics in a constructive mode would be very different from the orthodox theory of individual rational behaviour, equilibria - whether game theoretic or not - and, above all, the associated solutions (particularly via existence proofs, typically of equilibria).

Incidentally, many in economics contrast a 'digital proof' with a so-called 'analytical proof'. If what is meant by a 'digital proof', those theorems that are provable by programming a digital computer, then every analytical proof, say in standard textbooks on constructive analysis (Bishop, 1967; Bishop \& Bridges, 1985 or Bishop \& Cheng, 1972) ${ }^{24}$ is a digital proof. If by proof is meant, say, those sanctioned by intuitionistic logic only, then practically every so-called proof in almost any kind of formalised economic theory fails to be acceptable. Even if not underpinned by intuitionistic logic, in many varieties of constructive analysis - for example in Bishop (1967) - no appeal will be made to the tertium non datur in cases where infinitary instances have to be considered. Hence, any proof of a theorem in mathematical economics or game theory, derived with appeal to the Bolzano-Weierstrass theorem, cannot and will not be considered a valid proof existence. By now many are aware that both the Nash equilibrium and the Arrow-Debreu equilibrium are theorems whose proofs are based on the Brouwer ${ }^{25}$ (or Kakutani) fixed point theorem, but few note that this is mainly because the so-called proofs invoked the Bolzano-Weierstrass theorem, which makes them unimplementable on a digital computer underpinned by computable, constructive or non-standard mathematics.

In addition, every proof is a logico-mathematical argument. Now, every valid computer program is a 'kind of logico-mathematical argument', but what kind of logic and 
which branch of mathematics underpins a computer program? That will depend on whether one thinks of a computation in recursion theoretic of constructive sense.

However, Tymoczko's discussion of 'surveyability' of proofs (Tymoczko, 1979) suggests (p. 59) three characteristics of proof: that they should be convincing, surveyable and formalisable. He then goes on to claim that surveyability and formalisability 'are the deep features [of a proof]', and that (pp. 61-62; italics added):

It is because proofs are surveyable and formalizable that they are convincing to rational agents.

Surveyability and formalizability can be seen as two sides of the same coin. .... Can there be surveyable proofs that are not formalizable or formal proofs that cannot be surveyed? Are all surveyable proofs formalizable? .... Given any sufficiently rich theory, we can find a surveyable proof of a statement of that theory which has no formal proof. ...

Are all formalizable proofs surveyable? ... Here the answer is an easy no.

However, if we stop to think about this situation, it appears unlikely that this logical possibility can ever be realized. ....

In summary, although formal proofs outrun surveyable proofs, it is not at all obvious that mathematicians could come across formal proofs and recognize them as such without being able to survey them.

Surely, one cannot let these interesting remarks pass unchallenged! First of all, who or what is a 'rational agent'? It is entirely conceivable - and formally demonstrable (see, for example, Putnam (1967, [1975]), Velupillai (2000), especially chapter 3, and Velupillai (2010), especially parts II and IV) - that an effective characterisation of the behaviour of a rational agent in the sense of economic theory is formally equivalent to the computing activity of a Turing Machine. Next, Tymoczko is admirably clear in defining the concept of formalisability and formal proof - both by appealing to results in model and proof theory and to Gödel numberings of formal proofs considered as mathematical objects but does not define or characterise the meaning - formal or not - of surveyability! In the case of surveyability he falls back on intuitive concepts such as 'rational agents', humanly surveyable', 'recognise' and so on. Suppose, however, Tymoczko did formally define or characterise formally the notion of surveyability, in the same sense in which the intuitive notion of effective calculability was encapsulated in the formal notion of a Turing Machine or the $\lambda$-calculus, or partial recursive functions - all formally equivalent to each other by the Church-Turing Thesis. Then, it will be possible to show that a rational agent will not be able to recognise as surveyable the proof of some theorems by appealing to the Halting Problem for Turing Machines. Tymoczko's admirable and informal discussion is valid - formally, of course - only on the basis of an invalid asymmetry between his way of defining, implicitly, the notion of formalisability and formal proofs, but leaving to the intuitive domain the characterisation of surveyability. This makes the rest of his 'philosophical' arguments against accepting, for example, the Appel-Haken proof of the four-colour theorem much less than formally convincing.

There are many other ways we can cast seriously rigorous doubts against Tymoczko's loose, allegedly philosophical, arguments against considering 'computer-assisted proofs' as 'mathematical proofs', but this must suffice for the moment. ${ }^{26}$ Within this context of the discussion of computer-aided proofs, it may also be useful to mention that program verification is a part of denotational semantics (see Davis, Sigal, \& Weyuker, 1994). However, a serious discussion of program verification requires much more depth and understanding of the issue, for example as in Platek's crystal clear, almost pedagogic, yet deep, article (Platek, 1990). There are those who claim, for example, that "program 
verification is more difficult in practice than verifying an analytical proof' because 'there are simply more factors that can go humanly wrong.' It is easy to give many counterexamples to this kind of 'prejudice'.

Just off the cuff, we have in mind something that is of concern for us in our own research on economic dynamics: the (in)famous example of Dulac's Theorem, claiming to have 'proved' a theorem contributing to the resolution of the second part of the 16th of Hilbert's famous 23 Problems. ${ }^{27}$ It was published by Dulac in 1923; it was only more than half a century later, that the errors in the original proofs by Dulac were corrected, by Yulij Ilyashenko, and, independently, by Écalle $(1993)^{28}$ (see, for example, Dulac, $1923,{ }^{29}$ Perko, 1991, chapter 3 and Ilyashenko \& Yakovenko, 1995).

More pertinently, we would like to provide two examples of 'computer-aided' proofs, both executed with full cognizance of the difficulty of program verification but, at the same time, with rigorous and transparent criteria explicitly made to make sure that any 'factors' that 'can go humanly wrong' can be detected and corrected, if anyone wishes to do so. But more importantly, the first example shows the intimate way mathematical theory, experimental simulation and deep numerical analysis were brought to bear to resolve a long-standing paradox. The first is the very recent proof of the existence of the Lorenz Attractor (Tucker, 1999). In 1985, no less an authority on dynamical systems theory than Morris Hirsch observed, for the Lorenz System ${ }^{30}$ (Hirsch, 1985, p. 191; second set of italics added):

[C]haotic behaviour has not been proved. As far as I am aware, practically nothing has been proved about this particular system. ... It is of no particular importance to answer this question; but the lack of an answer is a sharp challenge to dynamicists, and considering all the attention paid to this system, it is something of a scandal.

In the same volume in which Hirsch's article appeared, another distinguished dynamical system theorist, Ralph Abraham, added his nuanced opinion - in softer phrases - to this 'scandal' (Abraham, 1985, p. 117; italics added):

The chaotic attractor of mathematical theory began with Birkhoff in 1916. The chaotic attractor of simulation experiment arrived with Lorenz in 1962. ... The identification of these two objects has not yet succeeded, despite many attempts during the past twenty years. Of course, everyone (including myself) expects this to happen soon ....

However, Abraham's own take on the 'scandal' was expressed in another way, a little further down (p. 118; underlined phrase in the original, italics added):

However, most of the time experimentalists observe not braids (rationally related frequencies) but quasi-periodic motions (apparently irrationally related frequencies). That is the quasiperiodic paradox. More than one scientists has lost faith in mathematics because of the ubiquity of this illegal motion in the natural world.

The most interesting point here is that the 'scientist lost faith in mathematics' because it was not able to make sense of the 'simulation experimentalists' observation.

Now, the Lorenz system is the paradigmatic repository of the property that almost characterises so-called chaotic dynamical systems: sensitive dependence on initial conditions (SDIC). For example, in the above case of the Lorenz system, can one expect the analyst, experimenter, simulator or whoever to be able to use the digital computer to faithfully replicate the dynamics of the continuous time-space Lorenz system's nonlinear dynamics - SDIC and all - 'exactly' (in any sense)? No serious experimenter, simulator, numerical analyst or even a mathematically competent dynamical system theorist would forget that the digital computer has its own way of truncating floating point representation 
of real numbers, depending on its internal, built-in, precision. A system of nonlinear equations, such as Lorenz's, susceptible to the problems of SDIC, cannot, therefore, almost by definition be represented 'exactly', if we interpret the phrase in its obvious, intuitive, way (for lack of a formal definition).

However, suppose we interpret 'exactly the same way' to mean that the numerical method that is implemented on the digital computer to simulate, experiment with, or analyse, the Lorenz system, should be mathematically equivalent to it, then we must ask what 'mathematical equivalence' entails. This is one kind of frontier research in the interface between nonlinear dynamics and theoretical numerical analysis, elegantly summarised in Stuart \& Humphries (1996).

Another way to make sense of this thorny issue of 'exactly' would be to construct a Turing Machine equivalent of, in this case, the Lorenz system. Then, of course, the question becomes: What is the meaning of 'Turing Machine equivalent? Again, a precise answer can be given (as we have tried, over the years and in many of our writings; cf., for example, Velupillai, 2000), so that one circumvents the pitfalls of discretisations and the rounding errors due to the computer's internal floating point (or 'fixed point' - not in the sense of the usual 'fix point' theorems) representations and truncations.

Finally, there is the fairly straightforward alternative of using interval analysis (cf., Moore, 1966) for the numerical method that is implemented in the digital computer to analyse, experiment or simulate the continuous time-space system, in this case, of course, the Lorenz system. It is this alternative that is chosen in Tucker's computer-aided proof of the existence of the Lorenz attractor (Tucker, op. cit., especially pp. 1200-1211).

But, surely, the existence of the Lorenz Attractor should be a classic analytical proof - perhaps utilising one or another (non-constructive) fix point theorem? Why, then, this preoccupation with 'discretisations' and 'presentations of exactly the same model' to a digital computer? For the same reasons that the proof of the four-colour theorem was achieved by Appel and Haken with the aid of a digital computer (see, for accessible, but quite complete details, Saaty \& Kainen, 1986, chapter 3). The parallels are even more than just the recourse to a digital computer to evaluate complex numerical calculations. In Tucker (op. cit., p. 1199), he begins with a classic mathematical method of an Ansatz, an intuitive hunch, which will, hopefully, be confirmed by the results of the complete analysis and necessary evaluations. The intuitive hunch is not a frivolous guess; it is an educated guess of the right starting point, based on a thorough knowledge of all possible aspects of an unsolved problem - in this case that of finding a correspondence between a mathematical object and an experimentally discovered one. In Tucker's Ansatz, normal form theory is combined with rigorously implemented digital computations are brought to bear on getting the desired final result. In deriving the normal form, an analytic change of coordinates leads to a classic small divisor problem, which to complete a necessary element of the analytic proof requires the numerical evaluation of 19,386 low-order divisors. ${ }^{31}$ It is here that the 'computer-aided' part of the proof acts as a 'scratch pad'.

Correspondingly, it is possible to identify the Ansatz in the Appel-Haken proof: it is a particularly well-informed probabilistic argument establishing, with almost absolute certainty that ${ }^{32}$ (Saaty \& Kainen, op.cit., p. 83; italics added):

[T]here must exist some discharging procedure producing an unavoidable set all of whose configurations are reducible. That is, they showed that the computer-assisted reducibility proof was overwhelmingly likely to succeed ... 
However, in these kinds of hybrid proofs, where the analytic (usually nonconstructive) and the numerical or combinatorial elements are brought to bear upon a procedure or a thought-experiment, the dividing line between the domain of the two has to be carefully distinguished. In Tucker's case, (1199):

a change of variables ... in a small cube centered at the origin, transforms the Lorenz equations ... into a carefully selected normal form... Inside the cube, we can then estimate the evolution of trajectories analytically, and thereby we avoid the problem of having to use the computers in regions where the flow times are unbounded.

The construction of the small cube, via the change of variables, entails 'an analytic change of coordinates, which ... introduces a small divisor problem', all 19, 386 of them, which then necessitates recourse to a digital computer and to interval analysis to compute, numerically, their estimates. The versatile Tucker wrote a 'small C-program, SMALLDIV.C' (Tucker, 1999, p. 1200) to estimate these small divisors.

An illustration of this point is made in Ruelle's report of one of Oscar Landford's computer-aided proofs (Ruelle, 2007, p. 100). ${ }^{33}$

My colleague Oscar Landford reported once on a theorem [whose] proofs [was] computer aided, which means that it consists of some mathematical preliminaries and then a computer program. The program (or code) uses interval arithmetic to check various inequalities; if these are found to be correct, the theorem is proved. The complications of the problem forced Landford to write a relatively long program, about 200 pages. .... Oscar Landford is a very careful person, and he took pains to check that, when the code is fed into the computer, the computer does exactly what it is supposed to do. In this manner - after the computer has agreed with the inequalities in the code - the proof of the theorem is complete.

Scarf's elegant, clear and complete exposition of the genesis of the CGE research program (Scarf, 1973), admirable though it is - and resides as the core fountainhead of the genesis of the core of current orthodoxy in the Neowalrasian cloisters, the real business cycle (RBC) model's RCE - simply does not confront the conflict between the analytical and the constructive or the computable domains. The interplay between the analytical and the numerical was bridged by the Uzawa equivalence theorem and the parallels with discharging procedures, unavoidable sets and reducibility can be identified with the construction of a specific sequence of primitive sets, replacement operations, labelling, etc. In fact, a study of the precise structure of the computer-aided nature of the establishment of Scarf's Theorem (Scarf, 1973, p. 45, Theorem 2.5.1) and its utilisation in demonstrating the original Brouwer fixed point theorem would be the starting point for a way to reduce the remaining indeterminacy in this research program (p. 51): the constructive or computable determination of 'a convergent subsequence of subsimplices ... which tend in the limit to a single vector $x^{*}$.' The missing link is an imaginative Ansatz. ${ }^{34}$ In its absence, the CGE program, followed by its uncritical application by the applied general equilibrium practitioners and, then, taken up even more uncritically by the RBC theorists, remains unfinished because (Scarf, 1973), p. 52:

The passage to the limit is the nonconstructive aspect of Brouwer's theorem, and we have no assurance that the subsimplices determined by a fine grid of vectors on [the price simplex] contains or is even close to a true fixed point of the mapping.

Yet the whole program has been accepted as having been successful in determining constructive and computable methods to locate Walrasian equilibria proved to exist by Arrow and Debreu, of course, non-constructively. This magic transformation of a nonconstructively derived uncomputable equilibrium, via an algorithm that appeals to an undecidable disjunction during its execution, is uncritically accepted by the inhabitants of the Neowalrasian cloisters and is taken to define - implicitly, of course - the 'perfect 
model' of the economist. This kind of economist knows, perhaps, instinctively, that there is no point in simulating anything, using a non-constructive algorithm, to find an uncomputable equilibrium

Finally, it may well be apposite to remember another aspect of computer-aided proofs - the candour and care with which those who appeal to the computer, at any particular stage of a proof, make available the codes and the kind of Ansatz that may have forced them to seek the aid of the computer, so that any interested person could repeat, check or whatever, the procedures adopted in the interface and by the computer. How many analytical proofs are made transparent in this way - particularly in the cloisters of mathematical economics?

\section{Reflections and bright hopes}

The vital discovery which made possible the analysis of a process of change, in properly economic terms, was the introduction of accounting procedure. While economists were fumbling around to find a set of categories by which they could make a formal analysis of economic change, other people were doing the job in a professional manner. In all its main forms, modern economic dynamics is an accounting theory. It borrows its leading concepts from the work of which had previously been done by accountants (with singularly little help from economists); and it is in accordance with this that social accounting should be its main practical instrument of application. Hicks (1956, p. 141); italics added.

It was fitting that Hicks, who considered himself An Accountant Among Economists (Klamer, 1989), made these observations in the Festschrift for Lindahl, himself the founding father of Macroeconomics underpinned by social accounting. There is no better exponent of this particular vision of modern economic dynamics as an accounting theory and social accounting as its main instrument of application than Lance Taylor. It is in this particular sense that we believe Taylor carries on the noble tradition of Petty, the Swedes of the Period of Shackle's High Theory - in particular, Lindahl, Myrdal and Svennilsson and the parallel work of Frisch in the same period, inherited by Leif Johansen, and the Keynes of How to Pay for the War (Keynes, 1940), from which the Political Arithmetic of Stone emerged. ${ }^{35}$ It was profoundly misleading for the computational economists who underpinned their economics in equilibrium and rationality to seek to claim they were working in the traditions of Leif Johansen, who was balancing accounts in a social accounting framework.

The numbers that make up a social accounting system - whether in formal matrix format or in any other scheme that allows the accounting balance, over time, of credits and debts, retrospectively or prospectively - are, at best, rational numbers. The founding father of Political Economy, Petty, laid the foundations for Political Arithmetic, in his opening statement in Political Arithmetick ${ }^{36}$

The Method I take to [carefully examin[e] whatever tends to lessen my hopes of the publick Welfare, is not yet very usual].. for instead of using only comparative and superlative Words, and intellectual Arguments, I have taken the course (as a Specimen of the Political Arithmetick I have long aimed at) to express my self in Terms of Number, Weight, or Measure; to use only Arguments of Sense, and to consider only such Causes, as have visible Foundations in Nature; leaving those that depend upon the mutable Minds, Opinions, Appetites, and Passions of particular Men, to the Consideration of others.

William Petty, Preface to Political Arithmetick (3rd ed., http://www.marxists.org/reference/ subject/economics/petty/); italics added

The natural data types of the 'number, weights and measures' in economics and finance are the integers or rational numbers. But almost without exception all economic 
and finance theorising assumes that observable data - or even digitally generated data, from these two spheres - are real numbers (or, in moments of enlightened weakness, one or another kind of the non-standard reals). How the real numbers of theory are related to the numbers that a digital computer can process, is never specified - at least not in any of the standard advanced (or even elementary) textbooks in economics, finance, IO, game theory or whatever. Maury Osborne's warning to traders in the stock market, not to approximate by the continuous that which is intrinsically discrete, ${ }^{37}$ made over a quarter of a century ago, has never been heeded by the 'traders' but, even worse, not even those who sometimes provide the hilfskonstruktion of computer programs for their 'mechanised' responses to actual events, represented by the ostensibly patterned data on computer screens:

As for the question of replacing rows of closely spaced dots by solid lines, you can do that too if you want to, and the governors of the exchange and the community of brokers and dealers who make markets will bless you. If you think in terms of solid lines while the practice is in terms of dots and little steps up and down, this misbelief on your part is worth, I would say conservatively, to the governors of the exchange, at least eighty million dollars per year. (Osborne, 1977 [1995], p. 34; italics added)

Hayes (2003) reminded us - at least those of us concerned with respecting the discrete and finite precision nature of digital computers - of the dangers of arbitrary approximations and routinised truncations of standard computations:

On February 25, 1991, a Patriot missile battery assigned to protect a military installation at Dahrahn, Saudi Arabia, failed to intercept a Scud missile, and the malfunction was blamed on an error in computer arithmetic. ... In combination with other peculiarities of the control software, the inaccuracy caused a miscalculation of almost 700 meters in the predicted position of the incoming missile. Twenty-eight soldiers died. (Hayes, 2003, p. 484; italics added)

What was this tragic 'error in computer arithmetic'? It is simply due to the fact the binary fraction for the decimal fraction $10^{-1}=0.1$ is not terminating:

$$
10^{-1}=(0.1)_{10}=(.0001100110011 \ldots)_{2}=(0001100110011 \ldots)_{2}
$$

In other words, the decimal fraction, in its binary notation, cycles and is nonterminating and will have to be truncated with unpredictable consequences, unless a serious approximation analysis is included in the software which truncates automatically for some predetermined instruction. But there is another alternative, in the case of pitfalls due to the discrete and finite nature of the digital computer and its arithmetic. This alternative would be to use interval analysis, where an 'interval of real numbers is treated as a new kind of number, represented by a pair of real numbers, namely its right and left end points' (Moore, 1966, p. vii; italics added). Had such numbers been used in the software that was built into the operation of the control software referred to above, the error would have been eliminated.

But there are, in fact, (at least) six ways of mathematical theorising where a computational basis is naturally embedded:

- Varieties of Constructive Mathematics and Constructive Analysis (Bridges \& Richman, 1987)

- Computability Theory and Varieties of Computable Analysis (Cooper, 2004, Weihrauch, 2000)

- Interval Analysis (Russian Constructivism, cf., Aberth, 2001, Moore, 1966, Moore, Kearfott, \& Cloud, 2009) 
- Real Computation (the 'Smale School', cf., Blum, Cucker, Shub, \& Smale, 1998)

- Smooth (Infinitesimal) Analysis (cf., Bell, 1998)

- Numerical Analysis (cf., Stuart \& Humphries, 1996)

We have, in a series of writings over the past decade (see many of the essays in Velupillai, 2010 and Velupillai, 2009), reflected on the nuanced differences in these mathematical theories, and their applications in economics. The interested reader is referred to them for more detailed information on these mathematical theories, their alternative logical foundations, the nature of their algorithmic underpinnings, and much else - for example, in particular, on the role (or non-role, as the case may be) of the Church-Turing Thesis in the different theories. If economic theorising eschews an underpinning in one or another of these mathematical theories, the computational claims and, hence, the feasibility and meaning of simulation by machine computation to explore their non-analytical aspects borders on the absurd (in the noble sense of The Theatre of the Absurd - pace Esslin).

We have argued that economic relationships, whether micro or macro, whether in game theoretic or IO modes, whether in finance or interindustrial analysis, should be formulated as Diophantine equations. Such equations, or systems of equations, are rarely algorithmically solvable, in general, without extensive simulational experiments which lead to new theoretical insights, encapsulated in innovative conceptual analysis. Essentially, the case we are putting forward is that the framework developed for studying and resolving Hilbert's Tenth Problem should be the paradigmatic one for any research field in economics, whose theoretical basis is underpinned by digital machine computation Consider, for example, the following three apparently 'simple' Diophantine equations (Poonen, 2008, p. 344), and ask the seemingly straightforward question whether they have solutions in integers:

$$
\begin{aligned}
& X^{3}+Y^{3}+Z^{3}=29 \\
& X^{3}+Y^{3}+Z^{3}=30 \\
& X^{3}+Y^{3}+Z^{3}=33
\end{aligned}
$$

To date, we know that the answer is in the affirmative for (8), and for (9), that the answer is 'yes' is known only since 1999 (the solution is: - 283059965, - 2218888517, 22204229320). However, (10) is still to be 'cracked'! Of course, in a strictly economic context, interpreting the right hand side as the available 'budget' for spending and the left hand side as the allocation of spending on three items - without bringing into play the motivational base for the alternative choices - it is clear one seeks solutions that are not only integer valued, but also non-negative. One must ask, in this context, why the mathematisation of economics, which claimed to go beyond the 'Walrasian' method of simply (sic!) counting equations and variables to ensure consistency and 'meaningful' solutions, did not go further than considering non-negative real values for economic variables? I have my own answers to this quasi-hypothetical question, but this is not the place to express and attempt to justify it.

In any case, continuing the theme of advocating a Diophantine approach to economic theorising and modelling, it may well be appropriate, at this point - and given many of the themes discussed above, particularly in Section 2, we might as well state the Diophantine conundrums of dynamics, from the point of view of computability, and hence, obviously, the importance of simulation to help resolve some, at least of the 'conundrums'. Indeed, to 
take up the subject discussed above, the Peano Existence Theorem for the IVP of ODE's, one of the frontier research results in applied recursion theory is the following, (see, Matiyasevich, 1993, chapter 9):

Theorem 17. There is no effective method for determining, for an arbitrary system of differential equations of the form,

$$
\begin{gathered}
P_{1}\left(x, \Xi_{1}(x), \ldots, \Xi_{k}(x), \Xi_{1}^{\prime}(x)\right)=0 \\
\ldots \\
\ldots \\
P_{k}\left(x, \Xi_{1}(x), \ldots, \Xi_{k}(x), \Xi_{k}^{\prime}(x)\right)=0
\end{gathered}
$$

where $P_{1}, \ldots, P_{k}$ are polynomials with integer coefficients, whether the system has a solution on the interval $[0,1]$.

This is just one representative result, in an important applied domain, derived using a uniform method of proof.

Essentially this means one has to resort to what we have called the Zabusky Precept to breach the algorithmic walls and make conceptual advances in economics in the Diophantine mode. Nothing less than simulation by machine computation of Diophantine dynamics should be the research program of economics.

Richard Stone was prescient, as he always had the penchant to be, when dealing with issues that had to do with computations, simulations, numerical collation of statistical data and quantitative modelling:

Our approach is quantitative because economic life is largely concerned with quantities.

We use computers because they are the best means that exist for answering the questions we ask. It is our responsibility to formulate the questions and get together the data which the computer needs to answer them.

Richard Stone, Foreword to Stone \& Brown, 1962 p. viii; italics added.

If we supplement this admonishment to the empirically oriented economic theorist, with David Deutsch's equally important - and eminently rigorous - insight, we - as economists - are well on the way to an empirically implementable algorithmic research program encompassing the triad of computation, simulation and dynamics indissolubly (Deutsch, 1985, p. 99):

Every finitely realizable physical system can be perfectly simulated by a universal model computing machine operating by finite means.

Deutsch enunciated the Turing Principle on the basis of a searching analysis of the meaning of the Church-Turing Thesis. He came to the conclusion that underpinning the Church-Turing Thesis there was a physical principle, which he enunciated as the above Turing Principle. Naturally, the Turing Principle, as given above, requires a precise statement of what is to be meant by 'perfectly simulated'. Deutsch, being the serious scientist he is, did not forget to add a definition of 'perfect simulation' (Deutsch, 1985, p. 99; italics added):

Definition 18. A computing machine $M$ is capable of perfectly simulating a physical system $S$, under a given labelling of their inputs and outputs, if there exists a program $\Pi(S)$ 
for $M$ that renders $M$ computationally equivalent to $S$ under the labelling. In other words, $\Pi(S)$ converts $M$ into a 'black box' functionally indistinguishable from $S$.

Much of our discussions above have had as a backdrop the precise theory of computation, which is underpinned by the Church-Turing Thesis. But we have also consciously adopted - although, we hasten to add, only pro tempore ${ }^{38}$ - Deutsch's important extensions, all of which seem to be consistent with the stand taken also by Gandy (1980), on the physical principles that will have to be the basis on which the Church-Turing Thesis is interpreted in computability theory. Even though we worked with an informal - but, hopefully, precise - definition of 'simulation', our arguments above have been made with the precise definitions of Deutsch in mind. It is, therefore, just as well, we state them precisely, at this concluding stage.

It is our belief, in this time and age, that economists with aims and ambitions to construct models and theorise with mathematical tools, should be exposed to the availability of a variety of mathematics and, correspondingly, different logical bases for them. To be taught mathematical economics as if real analysis and set theory are the be all and end all is absurd, especially when the next step is to use the mathematical models built on such foundations for computation by a digital computer, which is based on wholly different mathematical and logical principles: constructive mathematics and proof theory, on the one hand; or the theory of computation and recursion theory, on the other - with category theory in the wings to help us dispense with set theory altogether.

From our own experiences in teaching and interaction with colleagues, we are painfully aware that economists are, in general, blissfully ignorant of any notion of limits to computation, even with ideal machines. But even worse is the equally blissful ignorance on the intrinsic limits to the results obtained with real analysis, underpinned by set theory plus the axiom of choice, let alone the impossibility of adapting such results, from such domains, for computation on machines built on a wholly different mathematics - even with the most rigorous and careful notion of 'approximation'.

Economists have never shunned simulation. However, they may have misused it, perhaps due to a misunderstanding of the notion, nature and limits of computation, even by an ideal machine. Engineers do not attempt to design perpetual motion machines that violate the laws of thermodynamics or mechanics, although cranks, over the centuries, have claimed to have done so; most of the models emanating from work in economic theory belong to The Museum of Unworkable Devices ${ }^{39}$ - at least when viewed from the vantage point of constructive mathematics or recursion theory, i.e., from the point of view of computation. How those in the Walrasian, Neowalrasian and New Keynesian cloisters make their unworkable devices perform the tasks that need to be done, just for survival, is beyond our commonsense comprehension.

Surely, a strong case can be made for making economists, at least at the level of graduate pedagogy, aware of The Museum of Unworkable Devices and The Association for the Study of Failure (Shippai Gakkai)! An imposing catalogue of unworkable devices and their failures can easily be composed, entirely out of the products coming out of the above three - and other - cloisters, even without any mediation from constructive mathematics or recursion theory.

Only common sense of a universal variety and the ability to think logically preferably, but not necessarily, along the natural lines outlined by the Brouwerian Intuitionists - are required to understand, and work with, the above concepts, all of which are elementary in a deep mathematical sense. We have never found any advanced undergraduate or graduate student of reasonable maturity to have had any difficulty 
whatsoever with understanding the case we make for an economic theory framed in a mathematics that can handle these concepts. Since an economic theory encapsulating the possibility of, say, a computationally universal dynamical system, can only be explored by actual simulation - 'to collect specimens, to describe them with loving care, and to cultivate them for study under laboratory conditions' (Temple, 1958) - of the relevant system, it is natural for such students to realise that there is a wholly different world of economics than the one peddled by the purveyors of the ideas and tools emanating from the above cloisters.

No one equipped with the above concepts and their mathematical and epistemological underpinnings would dream of thinking that bounded rationality is some special subset of the economist's notion of rationality - the quintessential 'unworkable device'. No one who understands the ubiquity of non-maximum dynamical systems and understands the notion of computation universality would try to anchor a norm in equilibrium dynamics. No student of economics, equipped with these concepts, even at the level of nodding acquaintance, would feel comfortable in the Walrasian, Neowalrasian and New Keynesian cloisters, themselves located in Cantor's Paradise. It may well be apposite to end this long essay, a paen (we hope) to the triad of computation, simulation and dynamics in their epistemological settings, remembering the thoughts of two of the giants of 20th century mathematics and philosophy, David Hilbert and Ludwig Wittgenstein:

Hilbert (1925 [1926], p. 191): 'No one shall drive us out of the paradise which Cantor has created for us.'

Wittgenstein (1974, p.103): 'I would say, "I wouldn't dream of trying to drive anyone out of this paradise." I would try to do something quite different: I would try to show you that it is not a paradise - so that you'll leave of your own accord. I would say, You're welcome to this; just look about you.",

\section{Acknowledgments}

We are greatly indebted to the Editors and the anonymous referees of this Journal for detailed constructively critical suggestions and comments on earlier versions of this article. This final version is drastically revised and we have endeavoured to make it stand on its own, instead of being an 'immanent' critique of any other work. We are, as always, deeply indebted to Francesco Luna, Shu-Heng Chen, Selda Kao and Ragu Ragupathy for invaluable aesthetic advice, technical suggestions and scholarly comments. Alas, we alone are responsible for the remaining errors and infelicities.

\section{Notes}

1. Long before Zermelo gave it the name, axiom of choice, 14 years later.

2. An unfortunate example of this kind of infelicty can be found in Boumans, 2001, especially pages $74 \& 81$.

3. We suspect Cohen means 'solve mathematical problems', since 'solving mathematical theorems' seems a meaningless phrase.

4. The claims on computation in standard advanced microeconomics (e.g., Mas-Colell, Whinston, \& Green, 1995, especially § 20.D) or general equilibrium theory (e.g., Arrow \& Hahn, 1971, especially chapter 5 and $\S .5$ in Appendix C) are easily shown to be untenable from the point of view of any of the six mathematical frameworks for a model of computation, listed in the concluding section.

5. The discerning reader would easily recognise that we disagree quite comprehensively with the discussion, characterisation and visions of 'computational economics' in Mirowski (2002, especially in chapter 8, p. $523 \mathrm{ff}$ ). There are also at least five varieties of game theory: (vN-M/ Nash orthodox) Game Theory, Algorithmic Game Theory, Constructive Game Theory, Arithmetic Games and Combinatorial Games. Of these the second is really only an attempt at 
'algorithmising' orthodox game theory in the same sense in which computable general equilibrium theory tried to make computable sense of orthodox general equilibrium theory. The last three are intrinsically computational - with the third squarely in the constructive mathematics fold and the fourth (mostly) underpinned by classical recursion theory. Combinatorial game theory could be underpinned by either constructive or computability theory.

6. The word 'constructive' in the title of the article by Testfatsion (loc.cit) has nothing whatsoever to do with any 'variety of constructive mathematics'. The claims, definitions and characterisations of constructive mathematical aspects of agent-based economics in Epstein (2006, chapter 1) are technically incorrect. In particular, the characterisation of nonconstructive existence proofs in terms of acceptance of the tertium non datur, implying that the contrary in the case in constructive existence proofs (ibid, pp. 11-12), is not accurate (cf., Brouwer, 1908 [1975]). This is because the author has not stated the kind of tertiium non datur unacceptable in constructive mathematics. Above all conflating computability theoretic statements, themselves imprecisely stated, with constructive ones, makes the whole argument meaningless, from a mathematical point of view.

7. Once again we are in profound disagreement with the views expressed in Mirowski, 2002 on the origins and current status of this area of research. In particular, his technical discussions of the work of Alain Lewis (cf., Velupillai, Zambelli, \& Kinsella, 2011, for many of the published classics by Lewis and the Introduction, loc cit., for a summary of his contribution to the "protohistory' of the subject) are technically incorrect and misleading in many instances. Moreover, the technical contents of the letters by Lewis to Debreu, quoted on pp. 431-2 and pp. 526-7, of Mirowski, op.cit., contain serious errors, which makes the implications drawn in the text meaningless. In particular, the notions of combinatorial, finite and totally finite models, continuity and Peano Arithmetic are used, and referred to, by Lewis in unfortunately imprecise, indeed incorrect, ways. The juxtaposition of combinatorial and recursive analysis, on the one hand, and combinatorial and totally finite models is simply incorrect, from a purely mathematical point of view.

8. Our stance on this issue is reflected exactly by the view held by our friend, Lance Taylor. After attending the recent 50th anniversary celebrations of the Johansen Model, held in Oslo, Lance wrote as follows (E-mail to Velupillai, 27 August, 2010; italics added):

[Most participants at the] conference in honor of the 50th anniversary of Johansen's MSG model [held in Oslo in May, were] thinking that Leif was taking off from Arrow-Debreu when in fact he was doing disaggregated macro planning, moving around the numbers in a set of accounts that they had been constructed to satisfy. There is certainly no mention of A-D in his book.

9. Although even this admirable monograph is now - 13 years after publication - clearly out of date, given the massive research and results on variations of the Fermi-Pasta-Ulam (henceforth referred to as FPU) problem that have been, and are being, conducted at the frontiers of what has come to be called 'experimental nonlinear dynamics'.

10. One of the authors of this crystal clear exposition of the FPU problem, Norman Zabusky, was himself a pioneer in extracting new theoretical directions of research - and, indeed, together with his co-author, Martin Kruskal, to whose memory this particular article by Porter et al., is dedicated in (re-)discovering and giving a mathematical formalism to 'solitary waves', now called solitons. By retaining the original continuum domain of the FPU theoretical framework, and eschewing the discretisations necessary for digital computer implementation, they were able to predict the existence of solitons (see, in particular, Zabusky, 2005).

11. The field is a paradigmatic example of that classic approach Koopmans called 'measurement without theory'.

12. An egregious example of such an excessive and completely unfounded. in any kind of practice or theory - claim is the one made by Leijonhufvud (In his chapter, titled Agent-Based Macro [Tesfatsion \& Judd, 2006], p. 1626; italics added):

Agent-based computational methods provide the only way in which the self-regulatory capabilities of complex dynamic models can be explored so as to advance our understanding of the adaptive dynamics of actual economies.

Quite apart from the many undefined and even formally (unambiguously) undefinable concepts in this statement, the extraordinary claim that 'agent-based computational methods provide the only way' to understand anything, let alone of the 'adaptive dynamics of actual economies' 
must rank with the most foolish claims, even in a field replete with an embarrassment of riches of this class of assertions.

13. Zabusky's imaginative Visiometric approach was developed independently of Ralph Abraham's equally illuminating development of the Vismath vision for studying the geometry of dynamic behaviour (see, for example, [Abraham \& Shaw, 1984]).

14. Zabusky has almost from the outset of his sustained work on the Fermi-Pasta-Ulam problem used the word.synergize.in the sense in which it was first used, in a similar context, by Ulam (cf., [Ulam, 1960], chapter VIII, § 10):

I use the word 'synergetic' here to mean the enhancement in the rate and depth of mathematical understanding through the combined use of analysis and computer simulation.

May one be forgiven for wondering, in 'Nozick mode', if not simulation by a computer, then simulation by what?

15. We chose the 'characteristic' with the $1 / 2 x^{2}$ term, instead of the $x$ term only because we had severe difficulties of precision to get the kind of phase-plane dynamics we could have got with a computer capable of more precise computations.

16. This is only a sufficient condition and the 'admissible curve' is simply a formalisation of the traditional 'cubic characteristic' for the van der Pol equation. We conjecture that a 'counterintuitive' cycle in the sense defined above, can be shown to exist even without a 'cubic characteristic'; say, for example, with a 'characteristic' of the form: $\tau\left(\mathrm{e}^{\dot{x}}-2\right)$. Such a form would have only one isolated maximum or minimum.

17. A concise summary of the relevant results are:

Definition 13 Dynamical Systems capable of Computation Universality:

A dynamical system capable of computation universality is one whose defining initial conditions can be used to program and simulate the actions of any arbitrary Turing Machine, in particular that of a Universal Turing Machine.

Proposition 14 Dynamical systems characterisable in terms of limit points, limit cycles or 'chaotic' attractors, called 'elementary attractors', are not capable of universal computation.

Theorem 15 There is no effective procedure to decide whether a given observable trajectory is in the basin of attraction of a dynamical system capable of computation universality

Claim 16 Only dynamical systems capable of computation universality can generate behaviour that cannot be encapsulated in, or rationalised by, any notion of maximisation.

18. We must hasten to add that what we have referred to here, as the "counterintuitive notion of a trajectory attracted to an unstable manifold' is not an entirely new or fanciful notion for economics. It is a partial property of the famous Keynes-based Hicksian, piecewise linear, endogenous, model of the trade cycle (cf. Sedaghat, 1997).

19. But 'point' at what? At selecting, in the face of an undecidable disjunction, a particular subsequence from a closed and bounded sequence of which it is a member? Or does one point at the choice - i.e., a 'selection' - of an element from an uncountable infinity of sets, appealing to the axiom of choice? These are the kinds of selections and choices that are routinely appealed to, and claimed as feasible, in the proofs of theorems by orthodox mathematical economists

20. Of course, in all of the ensuing three counterfactual statements it is to a digital computer that reference is made. Only insignificant modifications need be made to our discussion if, instead of 'constructive', we had used 'recursion-theoretic'.

21. Presumably, one means 'computer behaviour', i.e., the underlying program on the basis of which the computer processes data, whether numerical or not.

22. For a representative, but not exhaustive, sample of such work, see Velupillai et al. (2011).

23. See the eminently readable text by Nordström, Petersson, and Smith (1990) for an elegant and accessible introduction to Martin-Löf's type theory, developed 'with the aim of being a clarification of constructive mathematics' (Nordström et al., 1990, p. 1). Several of the essays 
in [Crosilla \& Schuster, 2005], particularly chapters $1 \& 6$, are equally illuminative on the kind of approach to programming practicable computers with program languages developed for the specific purposes of encapsulating constructive mathematics.

24. See also the elegant and illuminative discussion on Algorithm in Modern Mathematics and Computer Science by Knuth (1981), where he states unambiguously (p. 94):

The interesting thing about [Bishop's Constructive mathematics] is that it reads essentially like ordinary mathematics, yet it is entirely algorithmic in nature if you look between the lines.

25. Of course Brouwer did derive, as mentioned above, 40 years after he first derived the nonconstructive version of the fixed point theorem that bears his name, a fixed point theorem based on intuitionistic logic, that had the express aim of avoiding any reliance on the BolzanoWeierstrass theorem (see the first footnote in Brouwer, 1952).

26. We should refer, here, to 'De Millo, Lipton, \& Perlis, 1979' (De Millo et al., 1979), to begin a discussion on program verification and to the counter-argument given with pungency and clarity by Fetzer (1988). Actually, however, the nuanced discussion in De Millo et al. (loc. cit) is far richer and more persuasive than a first reading may suggest.

27. The second part of Hilbert's 16th Problem remains unsolved, to this day.

28. Incidentally, Écalle's proof of Dulac's conjecture was constructive.

29. We must confess that we have never actually read the original by Dulac in the detail it deserves. Our own favourite text on this problem, which also gives a complete report on the rich Chinese tradition of research in this area, is the monograph by Ye Yan-Qian and his many collaborators, (Ye \& Others, 1986).

30. The Lorenz System is as follows:

$$
\begin{gathered}
\frac{\mathrm{d} x}{\mathrm{~d} t}=-10 x+10 y \\
\frac{\mathrm{d} y}{\mathrm{~d} t}=28 x-y-x z \\
\frac{\mathrm{d} z}{\mathrm{~d} t}=-\frac{8 z}{3}+x y
\end{gathered}
$$

31. The knowledgeable reader would immediately recognise the similarity with the origins of what eventually became the celebrated Kolmogorov-Arnold-Moser (KAM) theorem in dynamical systems theory. Small divisors, quasi-periodic orbits, perturbations (of Hamiltonians) - all issues we have had to mention in our various discussions, above - play significant parts in the motivation and the eventual formalisation Kolmogorov's original conjecture.

32. Having first produced 1936 reducible configurations, at least one of which had to occur in any planar triangulation.

33. In the spirit of complete honesty and candour with which we hope we have written this article, in fairness to the sceptics of the mathematical purity of computer-aided proofs, we must inform the reader the following fact. The continuation of the above quoted paragraph by Ruelle may be 'rather disheartening' to people like us, who believe that such proofs are on an equal footing, mathematically, to so-called 'analytical proofs'.

34. The Ansatz will have to find a way either to avoid any appeal to the Bolzano-Weierstrass theorem or to work directly with constructive mathematics without undecidable disjunctions. In fact, Brouwer's Intuitionistically corrected proof of his original theorem (Brouwer, 1952) is the solution - but only if the foundations of the theory developed in the Neowalrasian cloisters is redone in terms of constructive mathematics. Our own intuition is that ordinary economic theory, formalised on $\mathbb{N}, \mathbb{Q}$, or $\mathbb{Z}$, would avoid reliance on fix point theorems for the proof of equilibrium and, hence, would be amenable to a fruitful interaction of the analytic and the combinatorial to prove, with the aid of the digital computer, the existence of an equilibrium.

35. The third of the many books Sir John Hicks wrote (Hicks, 1942) was titled The Social Framework: An Introduction to Economics, of which the two chapters of the last part, Part $\mathrm{V}$, are entirely devoted to social accounting systems. Hicks began writing it around the time How to Pay for the War was completed and Stone began his work, under Keynes, in putting together the accounts to implement the Radical Plan for the Exchequer advocated in it. The Swedes had a head start on this - and Hicks was intimately aware of the Swedish work on 
social accounting as an underpinning for the emerging field of macroeconomics. We want to add here that Social Accounting is one thing; so-called Stock-Flow Consistent Modelling is quite another animal. Where the latter is non-trivial - which is a rare event - it is part of some meaningful Social Accounting System. Lindahl and Myrdal, in their work in the 1920s and 1930s, developing what later came to be called Macroeconomics, knew and worked within the discipline such awareness entailed.

36. We do not know why, when and how the $\mathbf{k}$ in Political Arithmetick disappeared!

37. We want to make it crystal clear that no where have we argued that all economic theorising should be in terms of so-called discrete models; nor have we ever supported the ridiculous suggestion that 'continuity' is irrelevant in economic theorising. Nothing in the kind of economics called computable economics, which we practice, has anything to do with these kinds of absurd claims.

38. This is partly because we are not completely convinced that the particular physical principle Deutsch derives and states as the Turing Principle encapsulates entirely, for example, Gandy's Principles for Mechanisms. It is the latter that we have usually worked with and have refereed to it as Gandy's Principles for Mechanisms. Of course, this also requires a precise definition of simulation, but which turns out to be slightly more complicated and lengthy to formulate than the admirably succinct definition derived by Deutsch. A deep and persuasive critique of Deutsch's Turing Principle can be found in Timpson (2004).

39. See the illuminating website dedicated to The Museum of Unworkable Devices: http://www. lhup.edu/dsimanek/museum/unwork.htm

\section{References}

Aberth, O. (2001). Computable calculus. London: Academic Press.

Abraham, R. (1985). Is there chaos without noise, Chapter 7. In P. Fischer \& W. R. Smith (Eds.), Chaos, fractals, and dynamics (pp. 117-121). New York \& Basel: Marcel Dekker, Inc.

Abraham, R. H., \& Shaw, C. D. (1984). Dynamics - The geometry of behaviour, part one: Periodic behavior. Santa Cruz, CA: The Visual Mathematics Library, Aerial Press, Inc.

Arrow, K. J., \& Hahn, F. H. (1971). General competitive analysis. Edinburgh: Oliver \& Boyd.

Bell, J. L. (1998). A primer of infinitesimal analysis. Cambridge: Cambridge University Press.

Bishop, E. (1967). Foundations of constructive analysis. New York: McGraw-Hill Book Company.

Bishop, E., \& Bridges, D. (1985). Constructive analysis. Berlin: Springer-Verlag.

Bishop, E., \& Cheng, H. (1972). Constructive measure theory. Providence, RI: American Mathematical Society.

Blum, L., Cucker, F., Shub, M., \& Smale, S. (1998). Complexity and real computation. New York: Springer-Verlag.

Boumans, M. (2001). A macroeconomic approach to complexity. In A. Zellner, H. A. Keuzenkamp, \& M. McAleer (Eds.), Simplicity, inference and modelling: Keeping it sophisticatedly simple Chapter 4 (pp. 73-82). Cambridge: Cambridge University Press.

Brattka, V. (2008). Plottable real number functions and the computable graph theorem. SIAM Journal on Computing, 38, 303-328. doi:10.1137/060658023

Braverman, M., \& Cook, S. (2006). Computing over the reals: Foundations for scientific computing. Notices of the AMS, 53, 318-329.

Bridges, D., \& Richman, F. (1987). Varieties of constructive mathematics. Cambridge: Cambridge University Press.

Brouwer, L. E. J. (1908 [1975]). De onbetrouwbaarheid der logische principes [The unreliability of the logical principles]. In A. Heyting (Ed.), L.E.J. Brouwer collected works: 1 - philosophy and foundations of mathematics (pp. 111-197). Amsterdam: North-Holland/American Elsevier.

Brouwer, L. E. J. (1952). An intuitionist correction of the fixed-point theorem on the sphere. Proceedings of the royal society, London, 213(1112), 1-2. doi:10.1098/rspa.1952.0106

Cohen, D. I. A. (1991). The superfluous paradigm. In J. H. Johnson \& M. J. Loomes (Eds.), The mathematical revolution inspired by computing (pp. 323-329). Oxford: Oxford University Press.

Cooper, S. B. (2004). Computability theory. Boca Raton and London: Chapman \& Hall/CRC Mathematics.

Crosilla, L., \& Schuster, P. (Eds.). (2005). From sets and types to topology and analysis: Towards practicable foundations for constructive mathematics. Oxford: Clarendon Press. 
Davis, M. (1978). What is a computation? In L. A. Steen (Ed.), Mathematics today - twelve informal essays (pp. 241-267). New York: Springer-Verlag.

Davis, M., Sigal, R., \& Weyuker, E. J. (1994). Computability, complexity, and languages: Fundamentals of theoretical computer science (2 ${ }^{\text {nd }}$ edition). Boston, MA: Academic Press, Harcourt, Brace \& Company.

De Millo, R. A., Lipton, R. J., \& Perlis, A. J. (1979). Social processes and proofs of theorems and programs. Communications of the ACM, 22, 271-280. doi:10.1145/359104.359106

Deutsch, D. (1985). Quantum theory, the Church-Turing principle and the universal quantum computer. Proceedings of the Royal Society of London, Series A, 400, 97-117. doi:10.1098/rspa. 1985.0070

Dixon, P. B., \& Parmenter, B. R. (2009). Computable general equilibrium modelling for policy analysis and forecasting. In H. M. Amman, D. A. Kendrick, \& J. Rust (Eds.), Handbook of computational economics Chapter 1 (Vol. 1, pp. 3-85). Amsterdam: North-Holland.

Dulac, H. (1923). Sur les cycles limites. Bulletin de la Société Mathématique de France, 51, 45-188.

Écalle, J. P. (1993). Six lectures on transseries, analysable functions and the constructive proof of Dulac's conjecture. In D. Schlomiuk (Ed.), Bifurcations and periodic orbits of vector fields (pp. 75-184). Dordrecht: Kluwer Academic Publishers.

Epstein, J. M. (2006). Generative social science: Studies in agent-based computational modeling. Princeton: Princeton University Press.

Fermi, E., Pasta, J., \& Ulam, S. (1955). Studies of non linear problems. Los Alamos Preprint, LA-1940, May.

Fetzer, J. H. (1988). Program verification: The very idea. Communications of the ACM, 31, 1048-1063. doi:10.1145/48529.48530

Feynman, R. P. (1996). Feynman lectures on computation. (A. J. G. Hey \& R. W. Allen Eds.), Reading, MA: Addison-Wesley Publishing Company, Inc.

Gandy, R. (1980). Church's thesis and principles for mechanisms. In J. Barwise, H. J. Keisler, \& K. Kunen (Eds.), The Kleene symposium. Amsterdam: North-Holland.

Goodwin, R. M. (1953). Static and dynamic linear general equilibrium models. In The Netherlands Economic Institute (Ed.), Input-output relations. Leiden: H. E. Stenfort Kroese, N. V.

Hardy, G. H. (1929). I.—mathematical proof. Mind, New Series, XXXVIII(149), 1-25. doi:10.1093/ $\operatorname{mind} / X X X V I I I .149 .1$

Hayes, B. (2003). A lucid interval. American Scientist, 91, 484-488. doi:10.1511/2003.6.484

Hicks, J. R. (1942). The social framework: An introduction to economics. Oxford: Oxford University Press.

Hicks, J. R. (1956). Methods of dynamic analysis. In 25 Economic essays in English, German and Scandinavian languages in honour of Erik Lindahl, 21 November (pp. 139-151). Stockholm: Ekonomisk Tidskrift.

Hilbert, D. (1925, [1926]). On the Infinite. In P. Benacerraf \& H. Putnam (Eds.), Philosophy of mathematics - selected readings (2nd ed., pp. 183-201). Cambridge: Cambridge University Press, 1983.

Hirsch, M. W. (1985). The chaos of dynamical systems, Chapter 12. In P. Fischer \& W. R. Smith (Eds.), Chaos, fractals, and dynamics (pp. 189-196). New York \& Basel: Marcel Dekker, Inc.

Ilyashenko, Y., \& Yakovenko, S. (Eds.). (1995). Concerning the Hilbert 16th problem, American Mathematical Society Translations Series 2 (Vol. 165). Providence, RI: American Mathematical Society.

Ince, E. L. (1944). Ordinary differential equations. Dover Publications: New York, NY.

Iserless, A. (1996). A first course in the numerical analysis of differential equations. Cambridge: Cambridge University Press.

Johansen, L. (1960; 1974). A multi-sectoral study of economic growth (Second enlarged edition). Amsterdam: North-Holland Publishing Company.

Keynes, J. M. (1940). How to pay for the war: A radical plan for the chancellor of the exchequer. London: Macmillan and Co., Ltd.

Klamer, A. (1989). An accountant among economists: Conversations with Sir John R. Hicks. The Journal of Economic Perspectives, 3, 167-180, Autumn. doi:10.1257/jep.3.4.167

Knuth, D. E. (1981). Algorithms in modern mathematics and computer science. In A. P. Ershov \& D. E. Knuth (Eds.), Algorithms in modern mathematics and computer science (pp. 82-99). Berlin: Springer-Verlag. 
Laugwitz, D. (2001). Curt Schmieden's approach to infinitesimals. An eye-opener to the historiography of analysis. In P. Schuster, U. Berger, \& H. Osswald (Eds.), Reuniting the antipodes - constructive and nonstandard views of the continuum (pp. 127-142). Dordrecht: Kluwer Academic Publishers.

Mas-Colell, A., Whinston, M. D., \& Green, J. R. (1995). Microeconomic theory. Oxford: Oxford University Press.

Matiyasevich, Y. V. (1993). Hilbert's tenth problem. Cambridge, MA: The MIT Press.

Mirowski, P. (2002). Machine dreams: Economics becomes a Cyborg science. Cambridge: Cambridge University Press.

Moore, R. E. (1966). Interval analysis. Englewood Cliffs, NJ: Prentice-Hall, Inc.

Moore, R. E., Kearfott, R. B., \& Cloud, M. J. (2009). Introduction to interval analysis. Philadelphia: SIAM (Society of Industrial and Applied Mathematics).

Nordström, B., Petersson, K., \& Smith, J. M. (1990). Programming in Martin-Löf's type theory. Oxford: Clarendon Press.

Osborne, M. S. M. (1977, [1995]). The stock market and finance from a physicist's viewpoint. Minneapolis, MN: Crossgar Press.

Palmgren, E. (2001). Unifying constructive and nonstandard analysis. In P. Schuster, U. Berger, \& $\mathrm{H}$. Osswald (Eds.), Reuniting the antipodes - constructive and nonstandard views of the continuum (pp. 167-184). Dordrecht: Kluwer Academic Publishers.

Perko, L. (1991). Differential equations and dynamical systems. New York: Springer-Verlag.

Platek, R. A. (1990). Making computers safe for the world: An introduction to proofs of programs: Part I. In P. Odifreddi (Ed.), Logic and computer science - Montecatini Terme, 1988 (pp. 60-89).

Plott, C. R., \& Smith, J. (1999). Instability of equilibria in experimental markets: Upward-sloping demands, externalities, and fad-like incentives. Southern Economic Journal, 65, 405-426. doi: $10.2307 / 1060807$

Poonen, B. (2008). Undecidability in number theory. Notices of the AMS, 55, 344-350.

Porter, M. A., Zabusky, N. J., Hu, B., \& Campbell, D. K. (2009). Fermi, Pasta, Ulam and the birth of experimental mathematics. American Scientist, 97, 214-221. doi:10.1511/2009.78.214

Putnam, H. (1967, [1975]). The mental life of some machines. In H. Castaneda (Ed.), Intensionality, minds and perception, Wayne University Press: Detroit; reprinted in: Mind, Language and Reality - Philosophical Papers: 2, by H. Putnam, Chapter 20 (pp. 408-428). Cambridge: Cambridge University Press.

Ruelle, D. (2007). The mathematician's brain: A personal tour through the essentials of mathematics and some of the great minds behind them. Princeton, NJ: Princeton University Press.

Saaty, T. L., \& Kainen, P. C. (1986). The four-color problem: Assaults and conquest. New York: Dover Publications.

Samuelson, P. A. (1970 [1972]). Maximum principles in analytical economics. Nobel Memorial Lecture, December 11, 1970; Reprinted In R. C. Merton (Ed.), The collected scientific papers of Paul A. Samuelson, Volume III , Chapter 130 (pp. 2-17). Cambridge, MA: The MIT Press.

Samuelson, P. A. (1974). Remembrances of Frisch. European Economic Review, 5, 7-23. doi:10. 1016/0014-2921(74)90004-X

Scarf, H. (1973). The computation of economic equilibria. New Haven: University Press.

Sedaghat, H. (1997). The impossibility of unstable, globally attracting fixed points for continuous mappings of the line. American Mathematical Monthly, 104, 356-358. doi:10.2307/2974585

Serény, G. (2011). How do we know that the Gödel sentence of a consistent theory is true. Philosophia Mathematica, 19, 47-73.

Stone, R., \& Brown, A. (Eds.). (1962). A computable model of economic growth, 1, A programme for growth. London: The Department of Applied Economics, Chapman and Hall.

Stuart, A. M., \& Humphries, A. R. (1996). Dynamical systems and numerical analysis. Cambridge, MA: Cambridge University Press.

Temple, G. (1958). Linearization and delinearization. In Proceedings of the international congress of mathematicians (pp. 233-247). Cambridge: Cambridge University Press.

Tesfatsion, L. (2006). Agent-based computational economics: A constructive approach to economic theory. In L. Tesfatsion \& K. L. Judd (Eds.), Handbook of Computational Economics Chapter 16 (Vol. 2, pp. 831-880). Amsterdam: North-Holland.

Tesfatsion, L., \& Judd, K. L. (Eds.). (2006). Handbook of computational economics - agent-based computational economics (Vol. 2). Amsterdam: North-Holland. 
Timpson, C. G. (2004). Quantum computers: The Church-Turing hypothesis versus the Turing principle. In C. Teuscher (Ed.), Alan Turing - life and legacy of a great thinker (pp. 213-240). Berlin \& Heidelberg: Springer-Verlag.

Tucker, W. (1999). The Lorenz attractor exists. C.R. Acad. Sci., 328, 1197-1202, Paris, t. 328, Série 1. doi:10.1016/S0764-4442(99)80439-X

Tymoczko, T. (1979). The four-color problem and its philosophical significance. The Journal of Philosophy, 76, 57-83. doi:10.2307/2025976

Ulam, S. M. (1960). A collection of mathematical problems. New York, NY: Wiley-Interscience.

Velupillai, K. V. (2000). Computable economics. Oxford: Oxford University Press.

Velupillai, K. V. (2007). Variations on the theme of conning in mathematical economics. Journal of Economic Surveys, 21, 466-505. doi:10.1111/j.1467-6419.2007.00511.x

Velupillai, K. V. (2009). A computable economist's perspective on computational complexity. In J. B. Rosser, Jr. (Ed.), The handbook of complexity research Chapter 4 (pp. 36-83). Cheltenham: Edward Elgar Publishing Ltd.

Velupillai, K. V. (2010). Computable foundations for economics. London: Routledge.

Velupillai, K. V., \& Kao, Y. -F. (2014). Computable and computational complexity theoretic bases for Herbert Simon's cognitive behavioural economics. Cognitive Systems Research, 29-30, 4052.

Velupillai, K. V., Zambelli, S., \& Kinsella, S. (Eds.). (2011). The Elgar companion to computable economics, the international library of critical writings in economics. Cheltenham, GL: Edward Elgar Publications.

Weihrauch, K. (2000). Computable analysis: An introduction. New York, NY: Springer-Verlag.

Weissert, T. P. (1997). The genesis of simulation in dynamics: Pursuing the Fermi-Pasta-Ulam problem. New York, NY: Springer-Verlag.

Wittgenstein, L. (1974). Philosophical grammar. Oxford: Basil Blackwell.

Ye, Y. -Q., \& Others (1986). Theory of limit cycles Translations of mathematical monographs, American Mathematical Society (Vol. 66). Providence, RI: American Mathematical Society.

Zabusky, N. J. (1981). Computational synergetics and mathematical innovation. Journal of Computational Physics, 43, 195-249. doi:10.1016/0021-9991(81)90120-0

Zabusky, N. J. (2005). Fermi-Pasta-Ulam, solitons and the fabric of nonlinear and computational science: History, synergetics and visiometrics. Chaos: An Interdisciplinary Journal of Nonlinear Sciences, 15, 015102/1-015102/16.

Zambelli, S. (2011). Flexible accelerator economic systems as coupled oscillators. Journal of Economic Surveys, 25, 608-633. doi:10.1111/j.1467-6419.2010.00664.x

Zvonkin, A. K., \& Shubin, M. A. (1984). Non-standard analysis and singular perturbations of ordinary differential equations. Russian Mathematical Surveys, 39, 69-131. doi:10.1070/ RM1984v039n02ABEH003091 